\title{
What brings your subjects to the lab? A field experiment
}

\author{
Michal Krawczyk
}

Received: 8 December 2009 / Accepted: 14 March 2011 / Published online: 29 March 2011

(C) The Author(s) 2011. This article is published with open access at Springerlink.com

\begin{abstract}
This paper reports a field experiment involving manipulation of invitations to register in an experimental economics subject database. Two types of invitations were sent out: one emphasizing pecuniary and the other non-pecuniary benefits of participation. The former resulted in higher response rate and the strength of this treatment effect was comparable in different groups defined by gender and academic major. In a follow-up test conducted about a year later it was found that individuals recruited by invitations emphasizing monetary benefits were less willing to make an effort to participate in a non-paid survey. The very same survey also showed that they were marginally less altruistic in general.
\end{abstract}

Keywords Experimental economics - Recruitment procedures · Incentives · Selection into experiments

\section{JEL Classification C9}

\section{Introduction}

Despite the explosive growth of the field of experimental economics, little research has been devoted to the question concerning the nature of subjects' motivation to come to the laboratory in the first place. If they are at least partly driven by anticipation of other than financial benefits of participating in experiments, by investigating them we may obtain clues that will help us understand behaviors seen as anomalous

I gratefully acknowledge helpful comments from the editor, Jordi Brandts, as well as two anonymous referees. I am also indebted to the administrative staff of the University of Warsaw who made this research possible.

M. Krawczyk (凶)

Faculty of Economic Sciences, University of Warsaw, Warsaw, Poland

e-mail: mkrawczyk@wne.uw.edu.pl 
in view of the standard theory. In particular, to the extent that these non-financial motives appeal to a varying degree to different groups, behavioral differences between them may be explained. One example is the observation that, in some contexts, female participants are more willing than the male ones to share resources with others (Eckel and Grossman 1998, see also Croson and Gneezy 2009). Similarly, a behavioral difference between students majoring in economics and in other fields is often reported (the former being more selfish and generally deviating less from the standard theory, see e.g. Frank and Schulze 2000). One way of understanding these tendencies is in terms of greater appeal of non-monetary benefits of participating in experiments for female and non-economist participants. Furthermore, to the extent that the necessity of using financial incentives in experimental economics is questioned or qualified (Read 2005), we would like to know whether other motivations are simply potent enough to assure participation of sufficient numbers of subjects. Finally, it is interesting to know how different perceived benefits shape patterns of selection of participants and thus their observed behavior.

Several types of non-pecuniary benefits of participation in experiments may be considered. To name but a few, (student) subjects may see an experiment as an interesting time-filler between classes or an opportunity to meet their colleagues and interact with them; they may take pride in and gain satisfaction from being able to contribute to the progress of science; they may be willing to please the experimenter (who may happen to be their professor) or they may think of experiments as a way to learn principles of economics (with less effort than necessary to study handbooks). Interestingly, some of the above-mentioned benefits seem to be more attractive to the students majoring in economics. While any of these alternative types of motivation may seem to be relatively weak in most subjects, it is not unreasonable to suppose that collectively they may sometimes be of importance when compared to that of the prospect of financial gains. This conjecture is the basis of the design of the current study, contrasting the appeal of the dollar against that of all alternative motivations taken together.

It may be difficult for the subjects themselves to assess the relative importance of their multiple participation motives in a questionnaire. Furthermore, some of these motivations may seem to be more socially desirable than others, thus biasing the results. A field experiment thus appears to be a more attractive method than a survey. I have therefore adopted this approach, comparing rates of response to two types of recruitment invitations, the first emphasizing the monetary rewards and the secondother benefits. As a follow-up, I compared (across these treatments) the willingness to fill in a non-paid survey, ${ }^{1}$ which, as a by-product, generated a measure of subjects' self-reported altruism.

Of course, this study is not the first one to manipulate invitations to experiments. The most closely related papers are in the field of psychology. To be sure, they focus on another type of experiments; furthermore, they almost exclusively investigate students of psychology as subjects and typically involve deception. MacDonald (1972) finds that subjects are more likely to volunteer to participate for course credit than for money or "for love of science". Also Sharp et al. (2006) conclude that extra credits

\footnotetext{
${ }^{1}$ I am indebted to a Referee who has suggested this line of research.
} 
result in higher sign-up rates. Studies also find that participants self-select to experiments with different descriptions, depending i.a. on gender and personality traits (Jackson et al. 1989; Senn and Desmarais 2001).

The few related studies in economics were also focused on the behavioral differences resulting chiefly from self-selection under different recruitment procedures. For example, Harrison et al. (2009) demonstrate that manipulating information about the show-up fee affects the risk attitude of the obtained sample. Eckel and Grossman (2000) find that subjects recruited in class tend to be more generous in the dictator game than real volunteers. List (2006) observes that sports-card sellers willing to participate in a lab experiment were more pro-social in the field than those who declined (albeit not significantly so). Noteworthy, Falk and Heckman (2009) claim that selection need not be viewed as a nuisance, especially given that it is possible to control subjects' demographic and psychological characteristics.

I am not aware of an empirical study comparing relative importance of different motivations to register as a subject in economics experiments.

The results of the current study show that the pecuniary motive dominates other considerations. This treatment effect did not interact with gender or academic major. In the follow-up it was found that individuals attracted by non-monetary benefits were more willing to complete a non-paid survey and declared themselves to be marginally more altruistic.

The remainder of the paper is structured as follows. Section 2 describes the design and procedures of the field experiment and the data set obtained, Sect. 3 presents the findings, and Sect. 4 contains a short discussion of the results.

\section{Design and procedures}

Students of four departments of the University of Warsaw, namely the Faculty of Economic Sciences, the Faculty of Law and Administration, the Faculty of Journalism and Political Science and the Faculty of Philosophy and Sociology were sent e-mail invitations to register at the local experimental economics recruitment site. ${ }^{2}$ The e-mail provided a link to the web page that mentioned benefits of participating in experiments. Two treatments were used in this respect. To slightly more than half of the subjects ${ }^{3}$ economic experiments were presented as a quick and easy way to make some money (Pecuniary Treatment, PT). The others were told that experiments would be enjoyable and would help the participants learn principles of economics in an interesting way; it was also emphasized that the experiments would be conducted as a part of research projects of the faculty as well as their colleagues (Non-Pecuniary Treatment, NPT). Here, the money was only

\footnotetext{
${ }^{2}$ ORSEE software (Greiner 2004) is used to manage this subject pool.

${ }^{3}$ I was not given access to the actual e-mail list but rather had to ask the university IT department to do the mailing for me. This is why I could not enforce the same number of subjects in each treatment. Partly for the same reason, the assignment was not explicitly randomized but rather based on the first letter of the student's last name, the upper part of the list receiving the Non-Pecuniary Treatment and the lower-the Pecuniary Treatment. I was not able to find any evidence that one's position in the alphabetical order of (Polish) last names correlates with traits, skills, academic achievements, etc.
} 
mentioned at the end and partly in a footnote. (The web pages translated from the Polish language are available at www.wne.uw.edu.pl/mkrawczyk/money.pdf and www.wne.uw.edu.pl/mkrawczyk/other.pdf respectively. The exchange rate, at the time, was about 1 PLN for 0.24 EURO, with typical simple student jobs paying about 15 PLN per hour.)

The e-mails were sent out in the third week of October (2009), the first month of the academic year in Poland. To the best of my knowledge, it was the first largescale recruitment campaign for economic experiments at the University of Warsaw and most certainly the first one advertising this particular ORSEE-based website. It appears that a non-negligible minority of non-first year economics students had participated in experiments run at the Faculty before; most of these were classroom ones, without monetary payments and sometimes involving deception. A small fraction of students might have also participated in experiments run at the Faculty of Psychology.

\subsection{Data set}

In total, 12,191 e-mails were sent out to non-economists, of which 7044 (58\%) to females. The faculty/institute/year breakdown is not known due to data confidentiality. However, it is certain that most were students of the large faculties of journalism and law. It is also likely that older students were underrepresented due to missing or incorrect entries in the e-mail database. As for economists, 908 students, predominantly those in their first or second year, were approached, of which 461 (51\%) were females. Among the subjects who did register, the precise response time was stored, along with several other variables including gender and academic major.

\section{Results}

In order to make comparisons of response rates in different groups, a decision had to be made regarding the period within which an invited participant had to register in the database in order to be counted as having responded to the invitation. Allowing only a short period of time would result in a low number of registrations and thus low statistical power. An overly long period, however, would increase the number of individuals consulting their registration decision with their colleagues-potential recipients of the other version of the invitation. This could dissolve the treatment effect. The time limit of 72 hours was picked out because it appeared that many students would not check their university mailboxes very often. In practice, analysis using other time spans ( 24 hours, 48 hours, 96 hours, etc.) delivers qualitatively analogous results; these are briefly mentioned below.

In total, of the 13,099 students approached, only 315 (2.4\%) responded within 72 hours. Table 1 shows response rates in different groups.

The following observations can readily be made. First, the PT was more effective than the other one. Overall it led to response rate of $2.8 \%$ (205 out of 7281) compared to $1.9 \%$ (110 out of 5818$)$ in the NPT. ${ }^{4}$

\footnotetext{
${ }^{4}$ This difference is highly significant $(p<.01)$. The same is true of the difference in registration rates for other time-spans such as 48 hours $(2.5 \%$ vs $1.8 \%, p<.01)$ or 24 hours $(2.1 \%$ vs $1.6 \%, p=.02$, two sided).
} 
Table 1 Response rates within 72 hours, by gender, academic major and treatment

\begin{tabular}{|c|c|c|c|c|}
\hline \multirow[t]{3}{*}{ Treatment } & \multicolumn{4}{|c|}{ Academic major and gender } \\
\hline & \multicolumn{2}{|l|}{ Econ } & \multicolumn{2}{|c|}{ Non-econ } \\
\hline & Male & Female & Male & Female \\
\hline Pecuniary & $20.0 \%$ & $16.0 \%$ & $2.0 \%$ & $1.6 \%$ \\
\hline Non-Pecuniary & $12.1 \%$ & $12.4 \%$ & $1.1 \%$ & $1.0 \%$ \\
\hline
\end{tabular}

Table 2 Registration within 72 hours: a probit regression

\begin{tabular}{llll}
\hline reg_72h & Coef. & Std. Err. & $P>|z|$ \\
\hline Non-Pecuniary Treat & -.156 & .078 & 0.044 \\
male & .108 & .064 & 0.094 \\
econ & 1.170 & .076 & 0.000 \\
male*Non-Pecuniary & -.102 & .106 & 0.338 \\
econ*Non-Pecuniary & -.016 & .120 & 0.892 \\
\hline$N$ & 13099 & & \\
Pseudo $R^{2}$ & .122 & & \\
\hline
\end{tabular}

This effect worked across all four groups (female economists, male economists, female non-economists, male non-economists). Indeed, the Pearson chi-square confirmed it at 5\% significance level - the only exception here is the female economists group. This suggests that pecuniary motivation played the decisive role for most participants of the study; when other possible reasons to participate were primed, the response rate fell. 5

Second, there seems to be very little interaction between the variables: gender and major, and the treatment variable. The main effect for economics, however, was very strong (positive) and highly significant. ${ }^{6}$

These findings are confirmed by the probit analysis shown in Table 2. While main effects of the variables econ and Non-Pecuniary Treatment are significant, the effect of male is only marginally significant and, more importantly, there is no interaction between the treatment and male or econ. When shorter time spans are used (registration within 24 or 48 hours), the coefficient on NonPecuniary Treatment is somewhat lower in absolute value ( -.135 and -.134$)$ and only marginally significant (.087 and 0.11 ) respectively. Similar to the results for the 72-hour span, econ takes values close to 1 and is highly significant while other variables are not.

\footnotetext{
${ }^{5}$ The results are qualitatively the same if registration within 24 or 48 hours is used instead, but due to overall lower rates, the difference is only significant for male non-economists and marginally significant for female non-economists.

${ }^{6}$ This effect is probably due to economists' lower costs of reaching the lab and greater familiarity with experimental economics as well as differences in the e-mail database quality.
} 


\subsection{Follow-up: behavioral differences a year later}

In order to obtain a measure of behavioral difference between the individuals attracted by the two types of advertisements the following procedure was implemented. In mid-November 2010, some 13 months after they were recruited, the 315 individuals who had signed up within 72 hours after the recruitment campaign received an email invitation to fill in an on-line survey. It was emphasized that while participation would help the researchers complete an important scientific project, no remuneration would be provided to the subjects. The survey was also described as anonymous and participants were not likely to expect any form of recognition. The decision to participate can thus be seen as a cheap but selfless act, evidence of other-regarding motivations to contribute to scientific research. Because the two groups that were initially subject to different treatments were sent different links, we can distinguish between responses of subjects originally in the PT from those in the NPT.

The survey itself was the Polish translation of the Self-Report Altruism Scale (Rushton et al. 1981). ${ }^{7}$ The inventory asks the subject to rate statements such as "I have given money to a charity" on a scale from "never" to "very often." Subjects also reported their gender and whether they studied economics or not. All questions were explicitly described as non-mandatory.

The hypotheses are that subjects who were initially attracted by the NPT will more often agree to partake in the survey, respond to more items and report more altruistic behavior.

Because the e-mail addresses used were those registered in the ORSEE database (i.e. presumably subjects' primary, regularly checked accounts), the response was very quick. Here, I use the responses recorded within the first 48 hours (using 24 or 72 hours instead would make very little difference).

Forty-three percent of the 110 NPT subjects approached responded to the survey, while in the PT the fraction was only $27 \%$ out of 205 observations. This is the difference that had been hypothesized and the Pearson chi-square test statistic is significant at one per cent level.

Potentially, this effect could have resulted from divergent expectations caused by the differentiated recruitment announcements rather than selection. In other words, those in the PT might refuse to take part in unpaid studies after they have been promised money. However, the plausibility of this explanation is questioned by the fact that some 13 months have passed between the recruitment and the follow-up study. Hence, subjects' expectations are likely to be entirely shaped by their experience in the meantime, not the original formulation of the invitations to register.

With regards to the completeness of the survey, it turns out that overall nearly all the questions (98\%) were answered, thus little can be said of the difference between the treatments.

The answers to the survey can be aggregated to the Self-Report Altruism Index (SRAI) which simply averages across all items taking the answer "never" as 1, "once" as 2 and so on. The index was then regressed on gender, academic major (econ/nonecon) and treatment in the recruitment procedure.

\footnotetext{
${ }^{7}$ Two items have been replaced with equivalents more suitable to local circumstances.
} 
Table 3 Determinants of self-report altruism

\begin{tabular}{llll}
\hline SRAI & Coef. & Std. Err. & $P>|z|$ \\
\hline Non-Pecuniary Treat. & .125 & .064 & 0.053 \\
male & -.184 & .061 & 0.004 \\
econ & -.162 & .065 & 0.015 \\
constant & 3.076 & .065 & 0.000 \\
\hline$N$ & 102 & & \\
adjusted $R^{2}$ & .126 & & \\
\hline
\end{tabular}

Table 3 shows that individuals recruited by means of the NPT are marginally more altruistic. We have to remember that this effect has probably been weakened by the second layer of selection - the obtained sample presumably contains the relatively altruistic among those in the PT as others refused to participate in the (unpaid) survey. We also see slightly lower altruism among economists and, consistent with some studies (Innocenti and Pazienza 2006), among males.

\section{Discussion}

This study allowed to investigate the motivations of experiment participants as reflected by their willingness to register depending on the aspects of participation in experiments that are emphasized. It appears that purely pecuniary motive is the main force driving subjects to the lab. This result is somewhat reassuring given the emphasis on financial incentives in experimental methodology in economics. At the same time, it suggests that providing monetary incentives may indeed be necessary to assure sufficient numbers of participants. This paper also contributes to the literature on self-selection into experiments, showing that different recruitment styles result in samples being more or less altruistic, both in self-reports and in actual behavior.

We do not find the interaction with gender or academic major as anticipated. It appears thus that if economists are found to behave more selfishly in experiments, it is not because they are especially money-oriented (while non-economists come to the lab for fun, education, etc.). The fact that the treatment effect was not any stronger in economists can be understood in terms of their interest in the educational aspect of experiments and the willingness to support the research efforts of the faculty.

Open Access This article is distributed under the terms of the Creative Commons Attribution Noncommercial License which permits any noncommercial use, distribution, and reproduction in any medium, provided the original author(s) and source are credited.

\section{References}

Croson, R., \& Gneezy, U. (2009). Gender differences in preferences. Journal of Economic Literature, 47(2), 448-474.

Eckel, C., \& Grossman, P. (1998). Are women less selfish than men?: Evidence from dictator experiments. The Economic Journal, 108(448), 726-735. 
Eckel, C., \& Grossman, P. (2000). Volunteers and pseudo-volunteers: The effect of recruitment method in dictator experiments. Experimental Economics, 3(2), 107-120.

Falk, A., \& Heckman, J. (2009). Lab experiments are a major source of knowledge in the social sciences. Science, 326(5952), 535.

Frank, B., \& Schulze, G. (2000). Does economics make citizens corrupt? Journal of Economic Behavior and Organization, 43(1), 101-113.

Greiner, B. (2004). The online recruitment system ORSEE 2.0-a guide for the organization of experiments in economics. University of Cologne, Working Paper Series in Economics, p. 10.

Harrison, G., Lau, M., \& Rutström, E. (2009). Risk attitudes, randomization to treatment, and self-selection into experiments. Journal of Economic Behavior and Organization, 70(3), 498-507.

Innocenti, A., \& Pazienza, M. (2006). Altruism and gender in the trust game. Labsi Working Paper, 5.

Jackson, J., Procidano, M., \& Cohen, C. (1989). Subject pool sign-up procedures: A threat to external validity. Social Behavior and Personality: An International Journal, 17(1), 29-42.

List, J. (2006). The behavioralist meets the market: measuring social preferences and reputation effects in actual transactions. Journal of Political Economy, 114(1), 1-37.

MacDonald, A. (1972). Characteristics of volunteer subjects under three recruiting methods: Pay, extra credit, and love of science. Journal of Consulting and Clinical Psychology, 39(2), 222-234.

Read, D. (2005). Monetary incentives, what are they good for? Journal of Economic Methodology, 12(2), 265-276.

Rushton, J., Chrisjohn, R., \& Fekken, G. (1981). The altruistic personality and the self-report altruism scale. Personality and Individual Differences, 2(4), 293-302.

Senn, C., \& Desmarais, S. (2001). Are our recruitment practices for sex studies working across gender? The effect of topic and gender of recruiter on participation rates of university men and women. The Journal of Sex Research, 38(2), 111-117.

Sharp, E., Pelletier, L., \& Lévesque, C. (2006). The double-edged sword of rewards for participation in psychology experiments. Canadian Journal of Behavioural Science/Revue canadienne des sciences du comportement, 38(3), 269-277. 